Revista Iberoamericana. Vol. LXII, Núms. 176-177, Julio-Diciembre 1996; 845-861

\title{
REPENSANDO LA HETEROGENEIDAD LATINOAMERICANA (A PROPÓSITO DE LUGARES, PAISAJES Y TERRITORIOS)
}

\author{
POR \\ Hugo Achugar \\ Universidad de la República, Uruguay
}

\section{Mundo y AldeA}

Mientras en el siglo XIX muchas sociedades de América Latina vivían el proceso de consolidación de una nación homogénea o la construcción de un estado único y todopoderoso, hoy estamos presenciando si no el estallido de la mencionada unidad nacional, por lo menos, su agudo cuestionamiento, su profunda modificación. En realidad, lo que parecería estar ocurriendo es que el llamado proceso de homogeneización/globalización opera a otro nivel que parece volver obsoletas tanto la escala como la propia categoría de nación; al menos eso es lo que algunos intelectuales y estudiosos han puesto sobre la mesa en el presente debate de este fin de siglo. Pero el debate no trata sólo de territorios sino también de lugares y de paisajes.

Cuando en el siglo pasado se comenzaron a plantear las ideas de integración de América Latina, la tensión entre mundo y aldea, conocimiento de lo local e ignorancia de lo planetario, persistencia de una mentalidad tradicional - o colonial-y aspiración a crear un nuevo repertorio de ideas tenía una dinámica particular. Estas ideas presuponían un paisaje tecnológico que era el del desarrollo contemporáneo de las comunicaciones y un paisaje político que era el de la situación geopolítica mundial y neocolonial. Hacia fines del siglo XIX, nuestros países estaban en pleno proceso de consolidación de los aparatos estatales o, en algunos de los casos, de lucha por la independencia. El paisaje étnico, cultural y social había sido remodelado en función de la supuesta armonía de un mestizaje más declarativo que real al mismo tiempo que las diferencias - potencialmente anticivilizatoriaseran erradicadas o sometidas a un autoritario proceso de homogeneización. Un proceso implícito en la consolidación del Estado y que suponía además y entre otros proyectos el de la educación universal. Por otro lado, la transformación de las comunicaciones había cambiado la percepción y la vivencia del tiempo y del espacio no sólo al interior de nuestra América sino también de éstos en relación con Europa y el resto del mundo.

Hoy, telematización y globalización mediante, tanto el acceso como la circulación del caudal de información han sido nuevamente transformados. Los estados nacionales están sometidos a un nuevo y doble desafío: por un lado, el constituido por la exigencia que el actual flujo económico-financiero o que el llamado neoliberalismo ha planteado en relación al tamaño del aparato estatal y al rol de las países periféricos y, por otro lado, el que los 
distintos procesos de integración regional o de constitución de zonas de libre comercio constituyen a las respectivas naciones. Las diferencias e integraciones presentan una dinámica propia y los paisajes culturales funcionan en varios y múltiples tiempos y direcciones.

Las transformaciones y los desafíos políticos, tecnológicos y sociales de nuestro presente siguen, sin embargo y de hecho, reproduciendo las jerarquías entre las clases sociales, entre las regiones y entre los países de los distintos mundos que cohabitan el planeta. Al mismo tiempo, no se ha logrado erradicar la existencia de estereotipos en la representación que los unos hacen de los otros. Más todavía, estas transformaciones continúan reproduciendo las representaciones culturales y políticas acerca del otro: se ubique el otro en la aldea, en el centro o en la perifieria.

Se podría preguntar, entonces, ¿en qué medida los cambios tecnológicos de los medios de comunicación y los procesos de integración regional en curso han transformado - si es que realmente han transformado algo - el modo de producción de las identidades locales o supranacionales? También se podría indagar la eventualidad de que las conductas de los sujetos sociales sigan operando atrapadas entre la inercia y la tradición a pesar de los cambios o "mutaciones civilizatorias" (Portantiero) que se han venido procesando en los últimos tiempos. Planteado lo mismo de otra manera se podría preguntar si ¿la transformación tecnológico-política ocurrida en los últimos tiempos — aludida en parte en esa realidad o efecto universalizador que se llama globalización - ha cambiado realmente las identidades locales y nacionales? O incluso se podría preguntar si ¿la tan mentada globalización ha estado o está construyendo una única y global identidad? O si por el contrario, las identidades múltiples, fluctuantes o migratorias de que se habla como uno de los fenómenos contemporáneos niega el supuesto de única y global identidad.

En primera instancia, creo poder afirmar que todas estas transformaciones no parecen haber variado la posición del sujeto tal como lo caracteriza José Martí hacia fines del siglo XIX; al menos en algunos aspectos. El aldeano vanidoso sigue existiendo en este presente aun cuando posea o no antenas parabólicas, esté enchufado a la radio, a varios canales de televisión - abierta, directa o por cable-, sea un adicto a la Internet, consuma diversos medios de prensa escrita, marcas de jean o clases de hamburguesas y sea ciudadano del eufórico Mercosur, del agónico Pacto Andino o del complicado Nafta.

La apreciación de Martí presuponía que el aldeano vanidoso ignoraba los gigantes que llevan siete leguas en las botas al igual que la pelea de los cometas en el cielo. Entre nosotros, los latinoamericanos de hoy, la imagen de aquel aldeano de Martí no ha desaparecido. La imagen del aldeano vanidoso centrado en la contemplación narcisista de su propia situación puede ser recogida sin mayores dificultades en nuestras sociedades; para ello alcanza con leer la prensa escrita de muchos de nuestros países o considerar la peripecia de algunos presidentes o de algunos intelectuales. La imagen del aldeano vanidoso, sin embargo, me importa en otro sentido - un sentido que podría llamar fuerte - donde aldeanismo se asimila con nacionalismo y regionalismo más que con narcisismo.

La imagen del aldeano martiano se relaciona con un nacionalismo o regionalismo aislacionista que, dado el enhebrado tecnológico, comunicativo y hasta cierto punto ideológico del presente fin de siglo, no parece muy creíble. Hay, sin embargo, otros lugares, otras fronteras no identificables con el desarrollo o el "progreso" tecnológico que permiten 
considerar la posibilidad de que ese aldeanismo subsista en medio del flujo cultural y migratorio de computadoras, faxes, correos electrónicos, políticas internacionales o asociaciones supranacionales. Más aun, dicho aldeanismo o fuerte localismo bajo la idea o la forma de la integración y de la identidad cultural es alentado no sólo y como podría pensarse por representantes de corrientes políticas "radicales" sino incluso por figuras como el director general del FMI Michel Camdessus, el presidente de Argentina Saúl Menem o el presidente Checo Vaclav Havel. ${ }^{1}$

¿En qué medida los sujetos sociales - a nivel nacional o simplemente a nivel de comunidades reducidas - han sido movilizados por la globalización o simplemente por la transformación tecnológica? ${ }^{2}$ Mejor aún, ¿la conexión telemática a que un número creciente de individuos ha sido sometido, en el mundo y en América Latina, opera como un elemento integrador a un imaginario único y homogéneo o, por el contrario, las peculiaridades locales operan como un desconstructor de ese imaginario global y transnacional? Algunas respuestas, como la de Cornejo Polar, proponen, en cierto modo, la posibilidad de receptores activos que no se limitarían a contemplar el vaciamiento de su tradición pues la recepción "implica un complejo proceso de reformulación y resemantización". ${ }^{3}$ La tensión puede ser o es más rica; sobre todo si se piensa que la eventual diversidad o fragmentación de las sociedades o comunidades nacionales produciría una decodificación múltiple del mensaje único. Esto confirmaría algo ya sabido, la heterogeneidad propia e histórica de nuestros países no permite imaginar una homogeneización inexorable. Por lo menos confirmaría que los procesos de penetración de culturas hegemónicas en América Latina no han supuesto ni es probable que supongan una uniformización aculturada.

Otro modo de considerar esto consiste en preguntar $i$ si el capital cultural que tiende a construir el mensaje global no supone una suerte de versión neoliberal de la multiplicidad heterogénea que atiende a la necesidad de los diversos y diferenciados nichos de mercado? En esta posibilidad, más que diversidad de recepción lo que habría sería una necesaria fragmentación del mercado y la globalización vendría a configurar, de hecho, una especie

\footnotetext{
${ }^{1}$ Al respecto ver lo señalado por Havel y por Camdessus en sus respectivas visitas a Montevideo durante el pasado mes de setiembre (El Observador, 27 de setiembre de 1996).

${ }^{2}$ También es posible argumentar que globalización y transformación tecnológica se implican la una a la otra.

${ }^{3}$ El pasaje completo dice así: "Ciertamente la subordinación supone una dinámica receptiva con relación a los códigos dominantes, pero esa recepción, salvo en casos de alienación aculturadora, no es pasiva; al revés, con más frecuencia y profundidad de lo que se piensa, implica un complejo proceso de reformulación y resemantización, siempre ligado a un previo ejercicio, también complejo, de asimilación y descarte. Tal vez influidos por los análisis menos sutiles del circuito de la comunicación, aquellos intelectuales (se refiere a los vinculados con la "teoría de la dependencia", H.A.) asumieron como válida la imagen del receptor como instancia pasiva, sólo reproductora, del mensaje del sujeto de la enunciación. No es así: el receptor, en este caso la literatura subordinada, es también un sujeto que produce significados propios, y esos significados no son meras variantes del sistema hegemónico de los sentidos y valores que este propone, sino procedimientos sutiles o contundentes que subvierten el orden de lo recibido" (Cornejo Polar, La formación de la tradición ..., 162).
} 
de macro-supermercado centralmente organizado pero de casi ilimitada oferta. ${ }^{4}$ Algo así como un "mobile" creado por Calder donde desde una estructura central previamente determinada se permitiera - realidad o simulacro - la diversidad y la multiplicidad de opciones. Esta posibilidad, como es evidente, no renuncia al relato que supone la unicidad del origen de la emisión y su inexorable función imperial.

¿En qué medida la transformación en la construcción de las identidades locales está regida por la tradición, por el rito o por la inercia y no por la globalización? La transformación que ofrece la globalización de un mundo telematizado opera sobre algo que la democracia restringida o la ilusión democratizadora de la televisión y de la Internet no ha logrado borrar: la existencia de sectores sociales fuertemente diferenciados por su nivel de ingreso económico. A lo que quizás, y sin quizás, habría que agregar la existencia de sectores o grupos fuertemente diferenciados por sus creencias religiosas así como por sus niveles educativos o de alfabetización. ${ }^{5}$

Más aun, la transformación de la globalización opera sobre la existencia de países y culturas también fuertemente diferenciados. Al respecto, la muy extendida creencia de que la globalización tiene un alcance planetario indiscriminado se estrella en parte con la existencia y la peripecia de países cuya cultura o cuyos gobiernos resisten fuertemente la globalización cultural e informativa. Al respecto, hay quienes sostienen (Arjun Appudarai entre otros) que la mentada globalización no es uniforme y que si en América Latina se equivale con norteamericanización, en Corea se equivale con japonización, en Armenia con rusificación, etc.

La existencia de tradiciones o herencias culturales que permiten combinar (mestizar, hibridar, transculturar) la hamburguesa de MacDonald con el mate uruguayo, la camiseta benetton con la zapatilla criolla de los gauchos, el personaje del comic con las movilizaciones sociales en el norte Argentino, los cultos umbandas con los desechos plásticos de las empresas transnacionales parece indicar un sustrato o una herencia cultural mucho más fuerte de lo que la versión demonizada del efecto globalizador parece creer.

Por otra parte, el discurso global de la sociedad telemática no es homogéneo ni siquiera en aquellos casos en que el discurso hegemónico tiene una presencia abrumadora. Babel, y no el muecín en el minarete o el sacerdote en el púlpito, parece ser la imagen que rige el presente espectáculo de nuestras sociedades. ¿Babel como imagen de la confusión y de la entropía o Babel como divisa liberadora del multiculturalismo? ¿Babel como estrategia de una economía global neoliberal o Babel como resultado de la resistencia cultural de los individuos?

\footnotetext{
${ }^{4}$ Algo de esto ha sido planteado tanto por Nelly Richard como por Martín Hopenhayn. En el caso de Richard sin embargo, la apuesta a una política de la diferencia como algo opuesto a la diferenciación propuesta por el mercado plantea algunos problemas que no consideraremos en esta oportunidad.

${ }^{5}$ En relación con la alfabetización se habla hoy de "analfabetos informáticos", analfabetos que en el caso de América Latina - aun teniendo en cuenta los enormes y vertiginosos esfuerzos e inversiones de los últimos años - son abrumadora mayoría; con lo que los "analfabetos tradicionales" pasan a ser "analfabetos dobles".
} 
La decisión depende de quién habla y sobre todo desde dónde habla. La decisión depende además de qué relato organiza la reflexión o la evaluación y sobre todo depende de qué institución - política, social, cultural o académica - se arroga la representación o la agencia del relato. Babel, zapping, rito, invención, aldea, centro, periferia son todos ellos más que términos, "lugares/problemas" desde donde pensar este presente. Creer que con la globalización ocurre un fenómeno fatal similar a del Big Ban es ignorar la existencia de aldeanos que continuan desconociendo la existencia de los gigantes Kentucky Fried Chicken o de las siete leguas de los Toyota Tercel. Incluso aunque el aldeano esté enchufado al show del chileno Don Francisco en Miami o al informativo de CNN, asista en directo y en vivo a los avatares de la Guerra del Golfo o participe vía Internet de una conferencia en el ciberespacio, la instrumentación que de ello realiza cada individuo en su vida cotidiana genera un producto simbólico distinto. Igual de distinto a como ocurría en el siglo XIX cuando los liberales brasileños eran al mismo tiempo esclavistas o cuando hoy ciertos jóvenes latinoamericanos - algunos de ellos izquierdistas - cantan y se entusiasman con grupos rockeros derechistas como "Guns and Roses" borrando o desestimando las implicaciones del discurso original y asimilándolo a sus precisas y locales circunstancias.

Pensar la globalización desde la periferia no significa necesariamente concluir que se está produciendo la homogeneización simbólica o política del planeta. El aldeano tiene un modo de producción más que híbrido tremendamente nacionalista y esa herencia cultural, ese capital cultural no es un desierto. Contra su supuesta defunción, la nación —entendida como conjunto de emociones, símbolos y sentimientos de pertenencia a una misma comunidad imaginada - sigue teniendo vigencia en amplios sectores de la cultura de América Latina aun cuando ya no se trate de la nación en la formulación homogeneizada del siglo XIX.

La supuesta ausencia de alternativa al modelo neoliberal globalizador y privatizador de un determinado sector de la cultura latinoamericana no significa ausencia de respuesta. De hecho se han propuesto diferentes respuestas. Respuestas que van desde la problematización de la nación tal como ha funcionado hasta el presente fin de siglo y que consecuentemente implican una relectura del pasado hasta respuestas que intentan problematizar la cultura masmediática tanto en su vinculación con el Estado como con las políticas o proyectos culturales de las elites.

Una de esas respuestas - una de esas que estamos viendo y viviendo- parece consistir precisamente en acudir al pasado, a la aldea, a la tradición, (y también al multiculturalismo) y desde allí resistir. Este tipo de resistencia, que se manifiesta de diversos modos, no supone, sin embargo, un proyecto alternativo duradero a largo plazo o al menos no presenta todavía otro proyecto que no sea una cerrada defensa del pasado. Una defensa que, a diferencia de la inamovibilidad del pasado implicada en el proyecto hegemónico, supone un anclaje en el proyecto de la modernidad y piensa que éste todavía es viable. En uno de esos modos o versiones se llega a posiciones restauradoras del espíritu romántico del anti-maquinismo.

Otras respuestas proponen la apuesta al desmontaje cultural como un modo de repensar o de resistir la indiferenciación anestesiante que suponen la globalización y los relatos oficiales u oficializados de la sociedad. Nelly Richard, por ejemplo, al considerar las posibilidades de resistencia cultural señala que 
.... es cierto que cargo el tono al hablar de "partidismo de la diferencia", pero siento que lo hago en proporción inversa a cómo la entonación predominante ha sido en estos años la de un pluralismo demasiado complaciente con una retórica fácil de la variedad y de la diversidad que se ha desplegado espectacularmente en toda la fachada mercantil de la cultura-evento. No creo que le corresponda a una práctica crítica la tarea de sintetizar el conjunto de actitudes que se supone representativas de la sociedad en general, aunque estas disposiciones de ánimo colectivo influyen obviamente en las condiciones de recepción social de las prácticas. Me parece que el gesto de una práctica crítica va, más bien, por el lado de poner a prueba los límites de aceptación del sistema, de probar su comprensividad o su tolerancia ejerciendo ciertas presiones de sentido sobre sus trazados internos y externos para modificarlos. Mientras la tendencia integradora del desarrollo cultural tiende a subrayary reforzar estos límites, la crítica cultural tendería más bien a descolocarlos, a someterlos a discusión. Ambas prácticas son necesarias, pero pareciera que todos los entusiasmos del momento concuerdan demasiado en sólo atender la función normalizadora y consolidadora de la primera de ellas (Richard, 117).

La posición de Nelly Richard parece orientarse hacia una suerte de micropolítica o de estrategia de resistencia focalizada. Una posición que no aspira a sintetizar o a hablar por el conjunto de la sociedad ni cree que sea posible o adecuado revivir proyectos "sesentistas". Lo cual no sólo supone abandonar planteos a largo plazo propios de la modernidad sino también supone objetivos si bien no "reducidos" al menos centrados en "focos" de asedio y resistencia.

En esta línea de pensamiento, el pasado no aparece como un lugar sagrado y desprovisto de conflictividad desde donde resistir el indiferenciado accionar del proceso de la globalización sino como un lugar/problema desde donde señalar los huecos de las historias oficiales así como los problemas de una resistencia potencialmente desactivadora.

... parte de la tarea crítica que le incumbe al pensamiento postdictatorial, junto la de resolver el conflicto entre asimilar (incorporar) o expulsar (rechazar) su pasado. Resolver críticamente este conflicto significa tanto evitar la nostalgia del Símbolo antidictatorial como resistir la empresa de desmemoria que busca reunificar la historia apaciguando a la fuerza sus fuerzas en disputa de sentido (Richard, 34).

En esta perspectiva, el pasado se convierte en un lugar desde donde construir el futuro pero sin que ello suponga su restauración y mucho menos su olvido. La dicotomía "asimilación/expulsión" respecto del pasado es planteada como un espacio no sólo de articulación de tiempos sino también de relatos. Relatos organizados por "nostalgias" o "desmemorias" que dan cuenta de la batalla/tarea del crítico cultural. Tarea descrita por Richard al plantear que "queda por imaginar el trabajo de una memoria que no sea la memoria pasiva del recuerdo cosificado, sino una memoria-sujeto capaz de formular enlaces constructivos y productivos entre pasado y presente para hacer estallar el 'tiempo ahora' (Benjamin) retenido y comprimido en las partículas históricas de muchos recuerdos discrepantes y silenciados por las memorias oficiales" (Richard, 32).

Las distintas respuestas, sin embargo, tienen como desafio o como riesgo la construcción de un paisaje que sea un simulacro nacionalista o que represente un nacionalismo de los sectores hegemónicos, lo que supone de hecho una instrumentalización gatopardiana de la 
globalización. O mejor aún, el riesgo para los latinoamericanos reside en la construcción de un relato nacionalista que olvida por imposición y no por elección, de un relato que construye su pasado desde un presente que silencia con autoritaria y represiva selectividad y que ofrece el paisaje plano de una reiterada y única versión homogeneizadora.

\section{REPENSANDO LA HETEROGENEIDAD}

En todo lo anterior subyacen algunos presupuestos, algunas nociones que operan en la reflexión latinoamericana como datos de la realidad o como verdades incontestadas. En ese sentido, la idea de la heterogeneidad es central al análisis de la cultura latinoamericana, tanto en un sentido histórico como en relación a la situación presente. Lo ha sido en el último cuarto de siglo aunque de hecho viene desde antes. Antonio Cornejo Polar, de modo protagónico, pero también críticos, antropólogos, sociólogos y pensadores como Néstor García Canclini, José Joaquín Brunner, Ángel Rama, Roberto Fernández Retamar, Renato Ortiz, entre muchos otros, han afirmado o reflexionado a partir de la heterogeneidad de la cultura latinoamericana.

Más aún, en torno a la heterogeneidad se han propuesto —antes y después- otras categorías de análisis no necesariamente idénticas pero sí afines o problemáticamente cercanas. ${ }^{6}$ Me refiero a las nociones de sincretismo, mestizaje, transculturación, hibridación e incluso, en una línea de pensamiento más reciente, la de la posmodernidad periférica o posmodernidad latinoamericana. ${ }^{7}$

Tal como sido planteada por Antonio Cornejo Polar, la heterogeneidad latinoamericana "caracteriza (...) la producción literaria peruana, andinay —en buena parte-latinoamericana" (Escribir en el aire, 27). Y esta característica, que se relaciona con la tensión entre las culturas orales y las letradas o escritas así como con la multiplicidad de los sujetos, tiene para Cornejo Polar, al menos respecto de la cultura peruano-andina, su fecha de nacimiento: "la tarde del sábado 16 de noviembre de 1532" (Escribir en el aire, 26).

\footnotetext{
${ }^{6}$ Antonio Cornejo Polar ha señalado la diferencia entre la "armonía desgarrada" o imposible del mestizaje - sobre todo a partir del Inca Garcilaso - y la heterogeneidad real de la cultura peruana, desmontando de ese modo toda fácil identificación entre ambas categorías. (Cornejo Polar, Escribir en el aire, 93 y siguientes). Por su parte, Néstor García Canclini ha señalado: "Se encontrarán ocasionales menciones de los términos sincretismo, mestizaje y otros empleados para designar procesos de hibridación. Prefiero este último porque abarca diversas mezclas interculturales - no sólo las raciales a las que suele limitarse 'mestizaje'-y porque permite incluir las formas modernas de hibridación mejor que 'sincretismo', fórmula referida casi siempre a fusiones religiosas o de movimientos simbólicos tradicionales" (Canclini, nota 1 de página 14). A su vez, Friedhlem Schmidt ha observado las diferencias y aún las enormes distancias entre la noción de heterogeneidad como la entiende Cornejo Polar y la de transculturación tal como la plantea Angel Rama. (“¿Literaturas heterogéneas o literatura de la transculturación?").

${ }^{7}$ Al respecto Néstor García Canclini sostiene que "Hoy concebimos a América Latina como una articulación más compleja de tradiciones y modernidades (diversas, desiguales), un continente heterogéneo formado por países donde, en cada uno, coexisten múltiples lógicas de desarrollo. Para repensar esta heterogeneidad es útil la reflexión antievolucionista del posmodernismo, más radical que cualquier otra anterior" (Canclini, Culturas hibridas, 23).
} 
La heterogeneidad descrita o presentada por Cornejo Polar parece ser indiscutible o por lo menos muy convincente. Lo que no resulta igualmente convincente es que dicha heterogeneidad sea un fenómeno exclusivo de la cultura latinoamericana. ${ }^{8}$ En ese sentido, es posible sostener que la articulación oralidad/escritura debe de haber estado presente en todos los contactos de los europeos con otros pueblos u otras culturas y no sólo en América Latina. Algo similar a los procesos constitutivos de la heterogeneidad debe de haber ocurrido - aunque no tengamos o al menos yo no conozca los registros - en Africa con la llegada de las distintas incursiones imperiales e incluso es posible argumentar que el encuentro entre una sociedad letrada y otra iletrada no fue tal o no lo fue en la calidad señalada. ${ }^{9}$ Más aun, es posible argumentar — como veremos más adelante- que la España previa a 1492 ya tenía en su acerbo y en su capital cultural la experiencia de encuentros y convivencias con pueblos y culturas fuertemente diferenciados. En este sentido, cabría preguntarse si los múltiples cruces y las diversas formas que adquirieron las producciones culturales resultantes de la convivencia multisecular de moros y cristianos no presentan aspectos similares a los que describimos bajo la noción de heterogeneidad en nuestra América. ${ }^{10}$

Las páginas que siguen apuntan a repensar la exclusividad que algunos han planteado o presupuesto al hablar de la heterogeneidad latinoamericana; ${ }^{11}$ en especial, a la luz de los procesos de transformación y globalización del presente fin de siglo.

\subsection{EMPEZANDO POR EL PAISAJE DE NUESTRA PERIFERIA}

No hace mucho sostenía ${ }^{12}$ que no era posible reflexionar sobre el imaginario de nuestro tiempo sin describir el lugar desde donde se habla o se reflexiona y sin dejar de inscribir el lugar desde donde se habla en aquello que se habla. ${ }^{13}$ Por lo mismo sostenía que pensar desde América Latina era pensar desde la periferia. Periferia no califica ni descalifica un pensamiento sino que lo sitúa.

\footnotetext{
${ }^{8}$ Argumento que Cornejo Polar no desarrolla pero que está implícito en sus ensayos así como en los de la mayoría de quienes trabajan con la noción de heterogeneidad respecto de la cultura latinoamericana. ${ }^{9}$ En este sentido, lo enfrentado no parece haber sido una cultura que carecía de toda forma de registro simbólico con otra que sí lo tenía y en forma muy sofisticada. Algo similar sostiene Sara CastroKlaren al afirmar, destacando la importancia de la "escritura" pre-hispánica en mesoamérica, que "el encuentro de 1492 no encaró a dos mundos marcados por insalvables disparidades respecto a la producción de textos y la consciencia que de ello se tenía" (citado por Cornejo Polar, Escribir en el aire, 36 , nota 28 ).

${ }^{10}$ La contraargumentación de que los "moros" pertenecían a una cultura escrita y no a una cultura oral no parece suficiente sobre todo por lo argumentado en la nota anterior.

"En un movimiento constante del pensamiento de García Canclini se tiende a identificar "culturas híbridas" y "heterogeneidad cultural", lo que lo lleva a afirmar que "el estudio de la heterogeneidad cultural (es) una de las vías para explicar los poderes oblicuos que entreveran instituciones liberales y hábitos autoritarios .... y plantearse como tarea el "estudiar las culturas híbridas que constituyen la modernidad y le dan su perfil específico en América Latina" (García Canclini, 15).

${ }_{12} \mathrm{Me}$ remito a lo desarrollado en La biblioteca en ruinas.

${ }^{13}$ El lugar por supuesto no refiere necesariamente a lo geográfico sino también a lo cultural.
} 
Sin embargo, reflexionar desde la periferia, plantea algunos problemas: empezando por la propia noción de periferia sobre todo si se pregunta: ¿qué significa la periferia en tiempos de globalización? O si se piensa que la globalización ha vuelto caduca la nociones de centro y periferia como sostienen, entre muchos otros, Appudarai y García Canclini.

De algún modo, la dirección de la presente reflexión apunta a tratar de entender el lugar/ problema del pensamiento latinoamericano en tiempos de globalización. Como sucede siempre, la pregunta, además de contener de algún modo la respuesta, tiene una temporalidad. Preguntar por la especificidad latinoamericana (no por afán de buscar una esencia o ciencia latinoamericanas, ése es un proyecto que tiene o tuvo su tiempo y su historia) en un momento en que la discusión se centraba - quizás todavía se siga centrando- por un lado, en los procesos (amenazas) de homogeneización cultural implícitos en uno de los posibles futuros de la globalización y, por otro, en la proliferación (exaltación) del multiculturalismo parece destinado al fracaso o practicar alguna forma de la obsolescencia.

Contra la globalización se esgrime - yo mismo he esgrimido- la heterogeneidad, el multiculturalismo, la fragmentación, etc. y de ese modo se aspira a desconstruir la homogeneidad del centro; ese centro supuestamente responsable o generador de la globalización actual. El centro, argumentaba, no es homogéneo pero sobre todo el centro también tiene sus periferias. Esto no significa, sin embargo, el rechazo total de la oposición centro-periferia como ha sido sostenido desde distintas posiciones y con propuestas diferentes.

En un sentido, parecería que la antigua conceptualización de centro y periferia ha sido descartada o sucedida por otra. En otro, la conceptualización de centro y periferia ha sido sustituida por una diferente, hoy hegemónica entre algunos intelectuales latinoamericanos (aunque no sólo entre éstos), que afirma algo similar a lo sostenido por Horácio Costa: "en un mundo descentralizado deja de dominar el esquema referencial centro/periferia: toda la humanidad, especialmente en términos culturales, está en el centro y está al mismo tiempo en la periferia".

Según esa línea de pensamiento, no habría ya centro ni periferia. Habríamos realizado el sueño del pibe periférico y seríamos todos centrales y todos periféricos. Una suerte de democracia universal habría ganado la galaxia cultural. El reino de los cielos sería de los sumergidos pero también lo sería el infierno. En ambos convivirían metropolitanos y aldeanos, centrales y marginales todos conectados en las autopistas informáticas y en las gigantescas redes/telarañas de la Internet.

Es posible encontrar grupos hegemónicos y subalternos en el centro; es posible encontrar en el centro relaciones de centro-periferia pero eso no quiere decir que haya caducado la oposición entre centro y periferia como parece proponer con mayor fuerza argumentativa Appudarai y como veremos más adelante. Lo que esto implica, entre otras cosas, es la idea de que el centro a nivel simbólico y discursivo está atravesado por desigualdades económico-sociales y también por problemáticas que surgen de las reivindicaciones de género, de raza y de orientación sexual. Significa además que ese centro o centros globalizadores piensan su realidad y la realidad planetaria en función de problemáticas vigentes en sus propios espacios y al hacerlo exportan/globalizan, deliberadamente o no, sus problemáticas. ${ }^{14}$

\footnotetext{
${ }^{14}$ Esta reflexión me llevaba a sostener que el espacio discursivo en la esfera pública - a nivel mundial,
} es decir tanto del primer mundo como de la periferia - se ha vuelto un espacio compartido donde se 
Es claro que ya no podemos seguir hablando en relación a la periferia, al centro y sus habitantes - reales o simbólicos - desde un nosotros que implique una universalización y una homogeneización total. Ejercer el plural e incluso el impersonal es, lo sabemos desde hace tiempo en América Latina, una forma de sojuzgación y de la apropiación de la voz del otro.

La mentada globalización - financiera, política, cibernética y cultural-presupone en su narrativa un perfil universal tanto de las sociedades periféricas como de los sujetos subalternos pero ese simulacro de homogeneidad, necesario a la estrategia o a la política de representación del centro, no logra borrar la compleja heterogeneidad del mundo real.

También hay periferias de la periferia. Aun dentro de los procesos de integración llámense Comunidad Europea, Nafta o Mercosur- existen centros y periferias y periferias de las periferias. Si el nosotros del Mercosur es el otro del Nafta o el otro de la Comunidad Europea, ese nosotros es plural, heterogéneo y, en cierto sentido, está atravesado por conflictos similares aunque no idénticos a los del centro o a los de los procesos de integración que ocurren en el centro globalizador. También es cierto que se ha propuesto que "nuestras identidades latinoamericanas en sus múltiples espacios y tiempos sean varias identidades, hasta tal punto que nos sea posible encontrar en nosotros varios 'yo' profundos" (Calderón). La postulación de una identidad universal del individuo aboliendo diferencias culturales, nacionales, de género, etnia, etc. puede ser tanto una forma de la homogeneización típica del discurso central como la cancelación del pensamiento pues reconoce el dato obvio: todos somos humanos. Y aunque reconocer el todo somos humanos puede servir para enfrentar desde el humanismo liberal al fascismo racista, no adelanta el conocimiento de los individuos. Lo mismo es válido si se pretendiera pensar en una identidad latinoamericana o mercosuriana; una identidad universal común a los países de América Latina o del Mercosur sólo parece ser posible de construir a partir del reconocimiento de la heterogeneidad propia.

La reflexión desde la periferia, entonces, está atravesada por múltiples presupuestos y estereotipos y genera actitudes variadas. Mirar desde afuera sirve, mirar desde adentro también. Lo que no sirve es mirar sólo desde afuera o sólo desde la región. Pero si corre gran riesgo el aldeano al postular su microespacio como el ónfalo del universo, igual o mayor riesgo corre el metropolitano al ignorar el margen o al dar cuenta del otro como un entomólogo al destripar un insecto en su laboratorio. La visión del metropolitano globalizador puede llevar, y de hecho demasiadas veces ha llevado, a postular al otro o la realidad simbólica del otro como un fenómeno digno del zoológico o como un dato

intenta construir o buscar una identidad nueva. No la identidad homogeneizadora impuesta por el monólogo del discurso imperial o nacional sino una identidad heterogénea, por diferenciada y plural, quizás más democrática y que respete las identidades otras. Esto supone, además, la preservación de la identidad discursiva frente a la supuesta validez universal no sólo de una única racionalidad discursiva sino de una única racionalidad escritural o argumental. Sin embargo ese posible movimiento discursivo en la esfera pública transnacional - al menos en la occidental - encierra otro intento de construcción de identidad o identidades. Me refiero al intento implícito en eso que se ha dado en llamar la globalización o el discurso de la globalización. La tensión entre procesos de integración regional y proceso de globalización son a la vez homólogos y opuestos. 
necesario a sus locales estrategias políticas. El otro muchas veces, aunque no siempre, ingresa en la reflexión del metropolitano como un ejercicio o como una ocasión para comprobar lo que ya ha decidido en su laboratorio es la Verdad (con mayúscula) para la periferia.

Los hombres o las mujeres de la periferia reflexionan siempre desde la periferia y esa marca de su enunciación atraviesa problematizando su discurso como no ocurre con el discurso del intelectual metropolitano aun cuando todos estén conectados vía Internet. Es decir, si bien el discurso metropolitano está marcado, en su caso el lugar de la enunciación no es problemático o cree no ser problemático. Después de todo para el metropolitano globalizador no existe otro lugar más que su lugar, otros valores más que sus valores, otro mundo más que su mundo y ése es el mundo que postula como válido para todos. La visión que los globalizados - sumergidos, marginales, periféricos o subalternos- pueden ofrecer aparece con relativa frecuencia ante los ojos de los metropolitanos como articulaciones discursivas descalificadas o primitivas. En ese sentido, el metropolitano siempre suele saber más y mejor lo que es bueno para el periférico.

La obvia relación entre periferia y centro descrita hasta ahora no significa, simplemente, una oposición primer mundo versus tercer mundo o, en particular, versus América Latina. También está presente al interior de nuestra América; por lo mismo, cuando pensamos los procesos de integración ya sea Mercosur o Nafta importa tener presente la obviedad que hemos venido señalando: no es lo mismo pensar desde San Pablo o desde Buenos Aires, que desde Chivilcoy, Asunción, Santa Cruz, Valparaíso, Salto o Punta del Este. Ni que hablar en el caso de México.

\subsection{Y SIGUIENDO POR NUESTRA EVENTUAL EXCLUSIVIDAD: TERRITORIO Y DESTERRITORIO}

Ahora bien, ¿sigue vigente, aún con todos los matices que hemos señalado hasta el momento, la oposición centro y periferia? Néstor García Canclini sostiene, comentando a Roger Rouse y de hecho adhiriendo al planteo, que la imagen que opone centro y periferia es también

... "expresión abstracta de un sistema imperial idealizado" en el que las gradaciones de poder y riqueza estarían distribuidas concéntricamente: lo mayor en el centro y una disminución creciente a medida que nos movemos hacia zonas circundantes. El mundo funciona cada vez menos de este modo, dice Rouse; necesitamos una cartografia alternativa del espacio social, basada más bien sobre las nociones de "circuito" y "frontera". (García Canclini, 292).

Las categorías de centro y periferia no parecen dar cuenta según Rouse del modo en que funciona el espacio social en el mundo contemporáneo. Si bien es posible que sea necesario volver a mapear, quizás no estaría de más incorporar en la nueva cartografia, un registro de la desigualdad. No creo que sea otra la aspiración de García Canclini; es decir, no creo que el planteo de García Canclini lleve a borrar una eventual cartografia de la desigualdad social. Sin embargo, el planteo de Rouse - con su aparente vocación de atender el contemporáneo fluir del tiempo- no parece atender necesariamente a los "arcaicos" 
marginales y desposeídos. Canclini comenta que para Rouse "tampoco debe suponerse ... que este reordenamiento sólo abarca a los marginales" (García Canclini, 292). Si bien es cierto que la nueva cartografía resultante del rediseño del espacio social impuesto por el proceso de globalización económico-financiero, no supone una ordenación de contigüidad espacial jerarquizada sino otro tipo de espacialidad relacional y situacional, también es cierto que la nueva cartografia se sobrepone a la anterior sin clausurarla. Es decir, lo que tenemos no es la abolición de una situación anterior por una nueva sino la coexistencia de múltiples ordenamientos, espacialidades y temporalidades. En ese sentido, centro y periferia como metáforas de "espacios del tener" y "espacios del carecer" siguen teniendo capacidad y validez hermeneútica.

Una argumentación más fuerte es la desarrollada por Arjun Appudarai quien al señalar que "El problema central de las interacciones globales del presente es la tensión entre homogeneización y heterogeneización cultural" propone que

La economía de la nueva cultura global debe ser vista como un orden complejo, sobrepuesto, disyuntivo que ya no puede ser entendido en términos de los existentes modelos de centro-periferia (incluso aquéllos que dan cuenta de múltiples centros y periferias).

(....) La complejidad de la economía global de hoy en día tiene que ver con ciertas y fundamentales disyunciones entre economía, cultura y política que apenas hemos comenzado a teorizar (Appuradai, 275).

La idea de disyunción de Appuradai implica la idea de fractura. Una idea que el mismo Appuradai entiende como central en las políticas de la cultura global. Esto lo lleva a proponer un marco teórico básico para investigar tales disyunciones que consiste en considerar la relación entre cinco dimensiones del flujo cultural global y que son: 1) los "etnopaisajes", 2) los “mediapaisajes", 3) los “tecnopaisajes", 4) los "financiapaisajes" y 5) los "ideopaisajes".

Estos paisajes serían o son ladrillos de lo que él llama — parafraseando a Benedict Anderson-mundos imaginados; "es decir, los múltiples mundos que son constituidos por las imaginaciones históricamente situadas de personas y grupos alrededor del planeta". Pero se trataría de paisajes que no sólo no encajan sino que, lejos de conjugarse, se sobreponen los unos a los otros.

En el planteo de Appuradai, la categoría de nación - y en cierto modo, incluso la de comunidad-, desaparece y es sustituida por varios universos o mundos imaginarios que coexisten en una relación que nada tiene que ver con procesos de dominación, hegemonía o espacialidades fisicas o políticas. En un sentido similar es que se viene hablando de "desterritorialización". Es, precisamente en esta cuestión, que está una de las claves del debate actual, ya que, si como dice Arjun Appudarai los medios de comunicación actuales crean un sentido de "no lugar", la espacialidad (o la concepción política) presupuesta o contenida en la tensión centro-periferia pierde o perdería sentido.

En esta línea de pensamiento no sólo la categoría o la tensión centro-periferia perdería sentido sino todo tipo de pensamiento que apuntara a la descripción de especificidades regionales, continentales o culturales, así como también la tensión hegemonía-subalternidad. Todo se resolvería en un nuevo espacio —en rigor un no espacio, un no territorio-que 
disolvería lo regional en lo planetario global; en un nuevo ordenamiento social y económico que disolvería la pertinencia de desigualdades y asimetrías. Lo que nuevamente parecería o posibilitaría plantear el tema de la indiferenciada universalidad; es decir que en cierto modo lo vigente sería la indiferenciación universalista y lo obsoleto estaría constituido por la categoría de comunidad nacional o continental y por la de región o subregión al quedar todas subsumidas en un tipo de comunidad independiente de clase, nación o región.

Si lo planteado por Appudarai fuera adecuado o "verdadero" ¿Qué pasaría entonces con la categoría de heterogeneidad tal como ha sido trabajada por muchos de nuestros estudiosos o intelectuales? No estoy totalmente convencido de la validez de lo planteado por Appudarai, en particular si lo consideramos en relación a América Latina donde el pasado tiene un peso particular. En los paisajes que describe Appudarai falta considerar, me parece, el peso que memorias, tradiciones e inercias tienen en la configuración de un paisaje que tiene que ver también con la identidad; algo así como un "memoriapaisaje" o "monumentopaisaje". Se podría argumentar que precisamente lo que cambia es, entre otras cosas, esa supuesta identidad y que por lo tanto carece de relevancia su consideración. Se podría sostener que la ruptura presenta las características de un cambio de paradigma o de un corte epistemológico y que por lo mismo los "memoriapaisajes" vigentes antes se vuelven obsoletos y por la tanto dejan de significar. Sin embargo, la lucha por el pasado y la memoria, como vimos antes en relación con Nelly Richard, ha sido y es particularmente relevante en América Latina.

En un cierto nivel, parecería que Appudarai tuviera razón y que la espacialidad desde donde se pensaba o desde donde nos pensábamos ha caducado. Sin embargo, si bien sería posible aceptar esta suerte de reformulación espacial, tecnológica y financiera donde centro y periferia perdería su sentido original, lo que se pierde parece no ser trivial. Se pierde nada menos y nada más que la consideración de las desigualdades en nuestros países y en nuestras sociedades.

Todo esto vuelve necesario repensar no sólo las categorías de centro y periferia sino al mismo tiempo vuelve necesario repensar la heterogeneidad latinoamericana. En ese sentido, creo que la pregunta acerca de de la tensión entre homogeneidad y heterogeneidad en relación a nuestra América debería ser replanteada tanto dentro como fuera de los términos de centro/periferia, global/local, mundo/aldea. La tensión parece residir entre lo propio y lo ajeno, lo específico y lo general o formulando lo mismo de otra manera: ¿Por qué entender lo propio como exclusivo y específico y en qué medida o de qué modo esto modifica nuestra reflexión?

Eso es lo que parece haber ocurrido con gran parte de nuestra reflexión sobre América Latina y eso es lo que quizás deberíamos repensar. Nos hemos deslizado de la descripción de un rasgo dominante de la cultura latinoamericana como es su heterogeneidad, a la postulación de ese rasgo como específico y de la especificidad a la exclusividad.

¿Por qué entender que lo heterogéneo es específico y exclusivo de América Latina cuando en otras partes del planeta ocurren o han ocurrido fenómenos que son similares o podrían ser similares? ¿No será que la conceptualización de la heterogeneidad está condicionada por las fronteras del paisaje ${ }^{15}$ contemplado? ¿En qué medida nociones como comunidad, nación, región, continente modifican la propia noción de heterogeneidad?

${ }^{15}$ Los múltiples paisajes considerados por Appudarai y especialmente por el "memoriapaisaje". 
No me refiero, en este momento, a lo planteado por Appudarai sino a lo que podríamos sintetizar en la pregunta ¿qué pasaría si consideramos la heterogeneidad latinoamericana de hoy en relación con la heterogeneidad presente en la España de 1490? O si consideramos otros países, otras regiones como plantea Roberto Fernández Retamar en Calibán; donde considera - en una posibilidad rápidamente dejada de lado - la eventualidad de que las características del proceso cultural y de la identidad latinoamericana sean similiares o idénticas a las de otras regiones del mundo. ${ }^{16}$

Permítaseme tomar un caso, seguramente no el único, como punto de comparación con nuestra América. El espacio socio-cultural que llamamos India fue comenzado a conquistar por Europa un poco antes de lo que llamamos América Latina. Incluso, antes de la llegada de los europeos ese territorio que conocemos como India había sido un espacio que había experimentado diversas conquistas. La heteroglosia, la diversidad étnica, la pluralidad religiosa, la cohabitación de más de una cultura e incluso la relación entre cultura hegemónica y cultura o culturas subalternas, entre culturas letradas y orales, se dio tanto en India como en América Latina. ¿Debemos concluir que no hay diferencias entre uno y otro continente? ¿Todo se soluciona recurriendo a nociones como sociedades poscoloniales 0 a la apaleada noción del Tercer Mundo? ¿No abre esta línea de razonamiento la puerta de atrás para que el humanismo universalista vuelva a proponer la identidad homogénea de todos los seres humanos? Y también ¿cómo poder distinguir entre las múltiples heterogeneidades de América Latina e India sabiendo como sabemos que la mera asimilación de América Latina con India es un salto al vacío y que la traslación de problemáticas y categorías válidas en una zona no necesariamente lo son en la otra?

Es obvio que proponer una u otra cosa se relaciona con agendas político-ideológicas y que ello es no sólo inevitable sino también legítimo. ¿Debemos abandonar la categoría de heterogeneidad como sinónimo de algo exclusivo y específico? ¿La eventual específica y exclusiva heterogeneidad de nuestra América debe ser buscada en alguno de los paisajes que menciona Appuradai o en todos a la vez? ¿Será, como ha sido planteado (Moraña, 284), que la noción de heterogeneidad se ha adelgazado y debe ser sustituida por el análisis de los problemas implicados en la construcción del sujeto? O, quizás en lugar de plantearnos el problema como lo hemos venido haciendo deberíamos recurrir a categorías como hibridación (Canclini), transculturación (Ortiz- Rama), mestizaje (con toda su historia desde el Inca

\footnotetext{
16 "Aunque puede fácilmente defenderse la indiscutible tesis de que todo hombre es un mestizo, e incluso toda cultura; aunque esto parece especialmente válido en el caso de las colonias, sin embargo, tanto en el aspecto étnico como en el cultural es evidente que los países capitalistas alcanzaron hace tiempo una relativa homogeneidad en este orden. (...) Tampoco puede establecerse acercamiento necesario entre mestizaje y mundo colonial. Este último es sumamente complejo, a pesar de básicas afinidades estructurales, y ha incluído países de culturas definidas y milenarias, algunos de los cuales padecieron (o padecen) la ocupación directa - la India, Vietnam-y otros la indirecta - China-; países de ricas culturas menos homogéneos políticamente, y que han sufrido formas muy diversas de colonialismo -el mundo árabe-; países, en fin, (...) En estos pueblos, en grado mayor o menor, hay mestizaje, por supuesto, pero es siempre accidental, simpre al margen de su línea central de desarrollo (Calibán, 8-9). Como se vera más adelante la posición de Retamar se hace, en cierto modo, eco de lo sostenido por Fernando Ortiz respecto de la transculturación ya que ambos autores parecen establecer entre los países "europeos" y Latinoamérica una diferencia basada en lo temporal.
} 
Garcilaso pasando por el siglo XIX hasta Benedetti). ¿Será que el modo de leer el proceso y la historia cultural de América Latina debe pasar por recorrer - una vez más y como parece hacerlo Roberto Fernández Retamar-, la dicotomía de la modernización en los términos de "civilización y barbarie", Ariel versus Calibán?

Más que respuestas tengo dudas y preguntas.

Todo esto supone un par de desafíos a las ciencias sociales pero también a la crítica cultural. Por lo menos supone un desafío a la noción de centro y periferia, a la de comunidad y a la propia noción de heterogeneidad. Todas deberían ser repensadas. Creo que supone incluso, por sobre todas las cosas, un replanteo de nociones como comunidad latinoamericana, su espacio o sus espacios, su tiempo o sus tiempos. Así como también deberíamos repensar el tema de las migraciones, los viajes y todos los desplazamientos en los territorios y no territorios del presente fin de siglo.

Por último, permítaseme brevemente, moverme en otra dirección. En algún momento del actual debate sobre la posmodernidad se ha aludido y debatido (tanto García Canclini en Culturas hibridas como Yúdice en On Edge) la idea de que la posmodernidad es o ha sido un fenómeno no sólo tradicional sino característico de América Latina. Y esto ha sido referido precisamente al tema de la heterogeneidad, una heterogeneidad que, en cierto sentido, se relaciona con problemáticas como las de la transculturación o la hibridación.

Es por eso que para terminar quisiera retomar el texto de Fernando Ortiz donde se acuña la expresión y el concepto de "transculturación". Ortiz apunta un par de cosas que me interesa destacar. En el momento de argumentar y defender el neologismo transculturación sostiene que:

Toda la escala cultural que Europa experimentó en más de cuatro milenios, en Cuba se pasó en menos de cuatro siglos. Lo que allí fue subida por rampas y escalones, aquí ha sido progreso a saltos y sobresaltos (Ortiz, 94$)$.

Y más adelante, llegado el momento de las definiciones sostiene:

Entendemos que el vocablo transculturación expresa mejor las diferentes fases del proceso transitivo de una cultura a otra, porque éste no consiste solamente en adquirir una distinta cultura, que es lo que en rigor indica la voz anglo-americana aculturation, sino que el proceso implica también necesariamente la pérdida o desarraigo de una cultura precedente, lo que pudiera decirse una parcial desculturación, y, además, significa la consiguiente creación de nuevos fenómenos culturales que pudieran denominarse de neoculturación (.....).

En conjunto, el proceso es una transculturación, y este vocablo comprende todas las fases de su parábola (....).

El concepto de la transculturación es cardinal y elementalmente indispensable para comprender la historia de Cuba y, por análogas razones, la de toda América en general (Ortiz, 96-97).

Creo no forzar en exceso la lectura de Ortiz si concluyo que la descripción/definición del fenómeno de la transculturación es aplicable a diversas sociedades, tiempos y regiones del planeta. La insistencia en la especificidad cubana y en segundo término latinoamericana 
de la transculturación no impiden observar, como el mismo Ortiz lo sostiene, que la diferencia con otros procesos similares - también vividos por Europa- radica sólo en la concentración temporal del proceso; lo que en un lugar tomó cuatro milenios en el otro, sólo cuatro siglos.

¿Sería posible, entonces, pensar que la especificidad/exclusividad de la transculturación (y de la, no necesariamente equivalente, heterogeneidad quizás también) latinoamericana en relación con otras regiones radica solamente en una dimensión temporal?

¿Tiempo, espacio, historia y muy especialmente la necesidad de narrar la sociedad y la cultura de América Latina es lo que nos ha llevado a pensar hasta el presente tal como hemos pensado? ¿Será necesario revisar entonces las categorías temporales, espaciales, históricas con que nos hemos leído? La conclusión está abierta e implica una relectura no sólo de nuestras sociedades sino también de nuestros pensadores, de pensadores y estudiosos como Antonio Cornejo Polar, Ángel Rama, Néstor García Canclini y muchos otros más. Esa es una tarea abierta de cara al futuro.

\section{BIBLIOGRAFIA}

Achugar, Hugo. La biblioteca en ruinas. Ensayos culturales sobre arte y literatura. Montevideo: Trilce, 1994.

Appudarai, Arjun. "Disjuncture and Difference in the Global Cultural Economy". The Public Phanthom. Bruce Robbins, ed. Minneapolis: University of Minessota Press, 1993.

Calderón, Fernando. "América Latina: Identidad y tiempos mixtos. O cómo tratar de pensar la modernidad sin dejar de ser indios". Davidy Goliath 52 (setiembre de 1987).

Costa, Horácio. Ponencia presentada en el encuentro "La palabra poética en América Latina: Evaluación de una Generación" realizado en México en 1990.

Fernández Retamar, Roberto. Calibán. Apuntes sobre la cultura en nuestra América. México: Diógenes, 1971.

Cornejo Polar, Antonio. La formación de la tradición literaria en el Perú. Lima: CEP, 1989.

Escribir en el aire. Ensayo sobre la heterogeneidad socio-cultural en las literaturas andinas. Lima: Editorial Horizonte, 1994.

García Canclini, Néstor. Culturas híbridas. Estrategias para entrar y salir de la modernidad. Buenos Aires: Sudamericana, 1992.

Hopenhayn, Martín. Ni apocaplípticos ni integrados. Aventuras de la modernidad en América Latina. Santiago de Chile: Fondo de Cultura Económica, 1994.

Moraña, Mabel. "Escribir en el aire, 'heterogeneidad' y estudios culturales”. Revista Iberoamericana 170-171 (1995): 279-286.

Ortiz, Fernando. Contrapunteo cubano del tabaco y el azúcar. Caracas: Biblioteca Ayacucho, 1978 (La Habana, 1940).

Portantiero, Juan Carlos. "Las propuestas socialistas. Hoy y mañana". Conferencia leída en Montevideo el 7 de octubre de 1993 (manuscrito).

Richard, Nelly. La insubordinación de los signos. Cambio político, transformaciones culturales y poéticas de la crisis. Santiago de Chile: Ed. Cuarto propio, 1994. 
Schmidt, Friedhlem. “¿Literaturas heterogéneas o literatura de la transculturación?”. Nuevo Texto Crítico 14-15 (junio 1994 - junio 1995): 193-199.

Yúdice, George, Jean Franco, Juan Flores, eds. On Edge: The Crisis of Contemporary Latin American Culture. Minneapolis: University of Minnesota, 1992. 
